IZA DP No. 4179

Optimal Family Policy in the Presence of Moral Hazard, When the Quantity and Quality of Children Are Stochastic

Alessandro Cigno

Annalisa Luporini

May 2009 


\title{
Optimal Family Policy in the Presence of Moral Hazard, When the Quantity and Quality of Children Are Stochastic
}

\author{
Alessandro Cigno \\ University of Florence \\ and IZA
}

Annalisa Luporini

University of Florence

Discussion Paper No. 4179

May 2009

IZA

P.O. Box 7240

53072 Bonn

Germany

Phone: +49-228-3894-0

Fax: +49-228-3894-180

E-mail: iza@iza.org

\begin{abstract}
Any opinions expressed here are those of the author(s) and not those of IZA. Research published in this series may include views on policy, but the institute itself takes no institutional policy positions.

The Institute for the Study of Labor (IZA) in Bonn is a local and virtual international research center and a place of communication between science, politics and business. IZA is an independent nonprofit organization supported by Deutsche Post Foundation. The center is associated with the University of Bonn and offers a stimulating research environment through its international network, workshops and conferences, data service, project support, research visits and doctoral program. IZA engages in (i) original and internationally competitive research in all fields of labor economics, (ii) development of policy concepts, and (iii) dissemination of research results and concepts to the interested public.
\end{abstract}

IZA Discussion Papers often represent preliminary work and are circulated to encourage discussion. Citation of such a paper should account for its provisional character. A revised version may be available directly from the author. 


\begin{abstract}

\section{Optimal Family Policy in the Presence of Moral Hazard,} When the Quantity and Quality of Children Are Stochastic

We examine the second-best family policy under the assumption that both the number and the future earning capacities of the children born to a couple are random variables with probability distributions conditional on unobservable parental actions. Potential parents take their decisions without taking into account the effects of these actions on the government's future tax revenue. The second-best policy provides parents with credit and insurance, and allows them to appropriate the external benefits of their actions.
\end{abstract}

JEL Classification: D13, D78, D82. H31, J13

Keywords: stochastic quantity and quality of children, moral hazard, population externalities, family allowances, scholarships, pensions

Corresponding author:

Alessandro Cigno

Università degli Studi di Firenze

Dipartimento di Studi sullo Stato

Via delle Pandette, 21

50127 Firenze

Italy

E-mail: cigno@unifi.it 


\section{Introduction}

Given that the quantity and quality of children are affected by parental decisions, is there any reason why the government should try to influence those decisions, and, if so, how? These issues have been addressed many times before in the literature, ${ }^{1}$ but the authors who have done so make one or both of two questionable assumptions. One is that the parental action which affects the quality of a child is observable by the government. This overlooks the possibility that the action could be either impossible or extremely costly for a public authority to monitor, and may thus lead to incorrect policy prescriptions. Cigno, Luporini and Pettini (2003) drop this assumption, and replace it with the one that child quality is a random variable with given probability distribution conditional on a parental action. Further assuming that the density function is common knowledge, but the conditioning action is private information, there is then a moral hazard problem. In the present paper, we continue to assume that a child's quality is a random variable with given density, but relax two subsidiary assumptions made in that article, namely that (i) a couple will necessarily set the conditioning action at the same level for all its children, and (ii) all these children will have necessarily the same quality if their parents set the action at the same level for all of them.

The other questionable assumption concerns fertility determination. In Cremer, Dellis and Pestieau (2003), the number of children is taken to be exogenous, but may vary across households. ${ }^{2}$ In Balestrino, Cigno and Pettini (2002), by contrast, this number is deterministically chosen by the parents. ${ }^{3}$ Both extremes are unrealistic, and may lead to incorrect policy prescriptions. The one that fertility is exogenous because it ignores the fertility effects of child-related policies. For example, as pointed out in Cigno (1986), a family allowance designed to reduce child poverty could result in a larger number of poor children, because it will induce parents to have more children, but possibly (if the substitutioneffect prevails over the income-effect) also to spend less on each of them. The one that fertility is a choice variable may lead to incorrect policy prescriptions because it identifies the action of procuring a certain number of births with its outcome. As the latter is observable, a government can then dictate how many children a couple should have by threatening a sufficiently severe penalty in case of disobedience. Therefore, the

\footnotetext{
${ }^{1}$ For a survey, see Cigno (2005).

${ }^{2}$ In much of the optimal taxation literature the number of children is not only exogenous, but also the same (usually zero) for all households.

${ }^{3}$ In Cigno, Luporini and Pettini (2003), already cited, the quality of the children is stochastic, but the number of births is deterministically chosen by the parents.
} 
government does not need to use costly incentives to get the socially optimal number of births. In the present paper, we depart from both these approaches by recognizing that, like the quality of a child, the quantity of children also is a random variable with probability distribution conditional on an unobservable parental action.

In the present context, there are two justifications for government intervention. The first is that, as quantity and quality are uncertain, couples will find it difficult to borrow against their children's expected earnings. ${ }^{4}$ Given, however, that the number of present and future tax payers is large, and assuming that the quantity of children born to different couples, and the qualities of these children, are independently distributed, the government does not face any uncertainty regarding future tax revenue, and will not have any difficulty in borrowing against this revenue. The government may thus be able to raise social welfare by lending to, and providing insurance for, would-be parents. The second justification relates to the presence of a population externality. The existence and nature of such an externality are among the questions left open by the optimum population literature. ${ }^{5}$ Many of the demonstrations provided by this literature are based on general-equilibrium arguments which do not apply to the partial-equilibrium setting adopted in the present paper. The only possible externalities, here, are fiscal. Given that today's children are tomorrow's tax payers, and provided that a child's quality can be measured by his or her future tax-paying capacity, a couple's behaviour will affect future tax revenue. As a couple has no reason to consider this effect, a purpose of policy is then to internalize the externality by allowing parents to appropriate their children's expected contribution to government revenue.

The policy optimization has a Principal-Agent structure, with the government in the role of principal, and couples in that of agents. Our modelling strategy bears similarities to that of Holmström $(1979,1982)$, but departs from it in two important respects. One is that the interests of the principal are not diametrically opposed to those of the agents. In our model, the government in fact maximizes the sum of the objectivefunctions of the potential parents. The other is that our model has a dynamic programming structure.

\footnotetext{
${ }^{4}$ The moral hazard problems which arise from the fact that the probability distributions of the quantity and quality of children are conditioned by unobservable parental actions make it difficult for a private lender to buy insurance against the risk of default.

${ }^{5}$ See Eckstein and Wolpin (1985), Michel and Pestieau (1993), Peters (1995), Razin and Sadka (1995), and Sinn (2004).
} 


\section{The model}

There are $N$ ex-ante identical agents. ${ }^{6}$ At date 1 , agent $i=1,2, \ldots, N$ takes an unobservable action $b^{i}$, which we interpret as reproductive activity. At date 2 , the number of children born to agent $i$, denoted by $n^{i}$, is revealed to all concerned. Agent $i$ then takes a vector of unobservable actions, $\mathbf{a}^{i}=\left(a^{i j}\right), i j=i 1, i 2, \ldots, i n^{i}$. The vector of outcomes $\mathbf{x}^{i}=\left(x^{i j}\right)$ becomes known at date 3 . At that date, there are no more actions for $i$ to take. We interpret $a^{i j}$ as a broadly-defined educational investment in child $i j$, and $x^{i j}$ as the child's quality. Agents derive either direct or indirect utility from their children's quality. The principal derives utility from each agent's utility. We measure $a^{i j}$ as the sum of the money and the money-equivalent of the attention $i$ spends on $i j$ at date 2 , and $x^{i j}$ as the present value, at the same date, of $i j$ 's future tax payments. The justification for measuring quality in this way is that, for any given income-tax schedule, the tax paid is a monotonic transformation of the income earned.

The instruments at the principal's disposal are a general income tax, and two subsidies. The income-tax schedule is assumed given, but the two subsidy schedules are to be determined, and the choice will affect the direction of the redistribution. One of the subsidies is payable at date 2 , when the number of children is known. The other is payable at date 3 , when the children's tax-paying capacities are revealed. In general, the amount of subsidy to which an agent is entitled at any given date will depend on all the information available to the principal at that date. As the agents are ex-ante identical, we shall then write

$$
s^{i}=s\left(n^{i}\right)
$$

for the subsidy due to $i$ at date 2 , and

$$
y^{i}=y\left(\mathbf{x}^{i}, n^{i}\right)
$$

for the one due at date 3 . Agent $i$ chooses $b^{i}$ and $\mathbf{a}^{i}$ taking the incometax and subsidy schedules as given. The principal chooses the subsidy schedules taking account of how the $N$ agents will respond to the policy. Both the principal and the agents apply backward induction. The former announces $s($.$) and y(.,$.$) at date 1$.

Ex post, the utility of agent $i$ will be given by

$$
U^{i}=U_{1}\left(C_{1}^{i}\right)+U_{2}\left(C_{2}^{i}\right)+U_{3}\left(C_{3}^{i}\right)
$$

\footnotetext{
${ }^{6}$ The effects of differences in parental ability to make money or raise children are examined in Balestrino, Cigno and Pettini (2002), and Cigno, Luporini and Pettini (2004), in an adverse-selection context with deterministic fertility.
} 
where $C_{t}^{i}$ is $i$ 's consumption at date $t=1,2,3$, and the function $U_{t}($.$) is$ increasing and strictly concave. The budget constraints facing $i$ are

$$
C_{1}^{i}=m_{1}
$$

at date 1 ,

$$
C_{2}^{i}=m_{2}+s^{i}-c\left(n^{i}\right)-\sum_{j=1}^{n^{i}} w\left(a^{i j}\right)
$$

at date 2 , and

$$
C_{3}^{i}=m_{3}+y^{i}+\sum_{j=1}^{n^{i}} z\left(x^{i j}\right)
$$

at date 3 , where $m_{t}$ is $i$ 's after-tax income at date $t, w\left(a^{i j}\right)$ the cost of $a^{i j}$, and $c\left(n^{i}\right)$ that part of the cost of raising $n^{i}$ children which does not depend on $\mathbf{a}^{i}=\left(a^{i j}\right) .{ }^{7}$ The term $z\left(x^{i j}\right)$ may be interpreted as either the money-equivalent of the altruistic pleasure that $i$ derives from $x^{i j}$, or the actual money payment that $i$ will receive from $i j$ at date 3 conditionally on $x^{i j}{ }^{8}$ To make sure that $i$ 's maximand is concave, we take $c($.$) and$ $w($.$) to be increasing and strictly convex (increasing marginal costs of$ $n^{i}$ and $a^{i j}$ ), and $z($.$) to be increasing and strictly concave (diminishing$ marginal utility of $\left.x^{i j}\right)$. Assuming that $x^{i j}$ is larger than $z\left(x^{i j}\right)$, there is a positive fiscal externality.

Agent $i$ chooses $b^{i}$ and $\mathbf{a}^{i}$ taking $m_{t}$ and the subsidy schedules as given. The principal chooses the subsidy schedules taking account of how the $N$ agents will respond to them. Both the principal and the agents apply backward induction. The former announces $s($.$) and y(.,$. at date 1.

\section{Date-2 decisions}

As date 2 is the last decision date, we start by placing ourselves at that date. The number of children born to agent $i, n^{i}$, is now given, and known to everyone concerned. The principal then pays agent $i$ the subsidy $s^{i}$. Agent $i$ chooses the vector of educational investments $\mathbf{a}^{i}$.

Let $X$ denote the set of possible quality outcomes of each child. The outcome, $x^{i j} \in X$, will depend on $a^{i j}$, known only to $i$, and on a random shock, $\theta^{i j}$, with known density. As the realization of $\theta^{i j}$ is not observable by either the principal or the agent, while the realization of

\footnotetext{
${ }^{7}$ If $a^{i j}$ includes investment of $i$ 's time, $w\left(a^{i j}\right)$ includes an opportunity-cost, and $m_{2}$ is then to be interpreted as $i$ 's full income at date 2 .

${ }^{8}$ Cigno $(1993,2005)$ derives conditions under which it is in the interest of nonaltruistic adults to make such payments to their elderly parents.
} 
$x^{i j}$ is observable by both, we follow Mirrlees (1974) in treating $x^{i j}$ itself as a random variable with known density $f\left(x^{i j}, a^{i j}\right)$. Having assumed that the shocks are identically and independently distributed, the joint density of $\mathbf{x}^{i}$ conditional on $\mathbf{a}^{i}$, defined over $(X)^{n^{i}}$, is $\prod_{j} f\left(x^{i j}, a^{i j}\right)$.

Having interpreted $a^{i j}$ as an educational investment, the cumulative distribution of $x^{i j}$ associated with a higher value of $a^{i j}$ will first-order stochastically dominate the one associated with a lower value of the same variable. We assume that the likelihood ratio $\frac{f_{a^{i j}}\left(x^{i j}, a^{i j}\right)}{f\left(x^{i j}, a^{i j}\right)}$ is increasing in $x^{i j}$, and that the cumulative distribution of $x^{i j}$ is convex in $a^{i j}$. These are, respectively, the standard Monotone Likelihood Ratio (MLR) and Convexity of Distribution Function (CDF) conditions which ensure that $i$ 's expected date-2 expected utility is concave in $a^{i}$, and will allow us to use the agent's first-order conditions as incentive-compatibility constraints in the principal's optimization. ${ }^{9}$

\subsection{Agents}

The expected utility of agent $i$ is

$$
W_{2}^{i}=U_{2}\left(C_{2}^{i}\right)+\int_{(X)^{n^{i}}} U_{3}\left(C_{3}^{i}\right) \prod_{j} f\left(x^{i j}, a^{i j}\right) \mathbf{d} \mathbf{x}^{i}
$$

where $C_{2}^{i}$ is determined by (3), and $C_{3}^{i}$ by (4). As $\mathbf{x}^{i}$ is a vector of random variables, $i$ will choose the vector of actions $\mathbf{a}^{i}$ to maximize (5).

The first-order conditions for this optimization are

$$
-w^{\prime}\left(a^{i j}\right) U_{2}^{\prime}\left(C_{2}^{i}\right)+\int_{(X)^{n^{i}}} U_{3}\left(C_{3}^{i}\right) f_{a^{i j}}\left(x^{i j}, a^{i j}\right) \prod_{-j} f\left(x^{i k}, a^{i k}\right) \mathbf{d} \mathbf{x}^{i}=0
$$

where the $\prod_{-j}$ operator denotes the product of all the $i$ terms other than $i k=i j$, for each $i j$. These conditions tell us that $i$ equates the private marginal cost of $a^{i j}, w^{\prime}\left(a^{i j}\right) U_{2}^{\prime}\left(C_{2}^{i}\right)$, to the expected private marginal benefit, $\int_{(X)^{n^{i}}} U_{3}\left(C_{3}^{i}\right) f_{a^{i j}}\left(x^{i j}, a^{i j}\right) \prod_{-j} f\left(x^{i k}, a^{i k}\right) \mathbf{d} \mathbf{x}^{i}$. Substituting from (3) and (4), we can see that, for $s^{i} \equiv y^{i j} \equiv 0$, the private marginal cost is increasing, and the expected private marginal benefit decreasing, in $n^{i}$. The chosen value of $a^{i j}$, and the expected value of $x^{i j}$, will then be decreasing in $n^{i}$. This is the customary trade-off between quantity and quality of children.

\footnotetext{
${ }^{9}$ For a demonstration of this proposition in the standard single-agent context, see Grossman Hart (1983) and Rogerson (1985). For an extension to the multi-agent case, see Luporini (2006).
} 


\subsection{Principal}

With $n^{1}, n^{2}, \ldots, n^{N}$ given, the total value of the subsidies that the government is committed to pay at the present date, $\sum_{i=1}^{N} s^{i}$, is a given constant. Furthermore, as $N$ is large, and having assumed that the quality outcomes are i.i.d., the government does not face any uncertainty with regard to either the aggregate value of the subsidies, $\sum_{i=1}^{N} \int_{(X)^{n^{i}}} y^{i} \prod_{j} f\left(x^{i j}, a^{i j}\right) \mathbf{d} \mathbf{x}^{i}$, it will have to pay, or the aggregate tax revenue,

$$
\sum_{i=1}^{N} \int_{(X)^{n^{i}}} \sum_{j=1}^{n^{i}} x^{i j} \prod_{j} f\left(x^{i j}, a^{i j}\right) \mathbf{d} \mathbf{x}^{i} \equiv \sum_{i=1}^{N} \sum_{j=1}^{n^{i}} \int_{X} x^{i j} f\left(x^{i j}, a^{i j}\right) d x^{i j},
$$

it will receive at the next date. Therefore, the principal's problem is to choose $\mathbf{a}^{i}$, and a $y^{i}$ for each possible realization of $\mathbf{x}^{i},{ }^{10} i=1,2, \ldots, N$, so as to maximize

$$
W_{2}=\sum_{i=1}^{N}\left[U_{2}\left(C_{2}^{i}\right)+\int_{(X)^{n^{i}}} U_{3}\left(C_{3}^{i}\right) \prod_{j} f\left(x^{i j}, a^{i j}\right) \mathbf{d} \mathbf{x}^{i}\right]
$$

subject to the incentive-compatibility constraints (6), and to the budget constraint,

$$
\sum_{i=1}^{N} \int_{(X)^{n^{i}}}\left(\sum_{j=1}^{n^{i}} x^{i j}-y^{i}\right) \prod_{j} f\left(x^{i j}, a^{i j}\right) \mathbf{d} \mathbf{x}^{i} \geq \sum_{i=1}^{N} s^{i}
$$

where $s^{i}$ is now a given constant. There is no need for participation constraints because the agents must pay their income taxes anyway, and no agent will refuse a subsidy. It is clear from (8) that the policy will oblige the current child generation to subsidize the current parent generation. In its turn, however, the parent generation will have been required to subsidize the grandparent generation. ${ }^{11}$

The principal's first-order conditions tell us that $y^{i}$ must satisfy

$U_{3}^{\prime}\left(C_{3}\right) \prod_{j} f\left(x^{i j}, a^{i j}\right)-\lambda \prod_{j} f\left(x^{i j}, a^{i j}\right)+U_{3}^{\prime}\left(C_{3}^{i}\right) \sum_{j=1}^{n^{i}} \mu^{i j} f_{a^{i j}}\left(x^{i j}, a^{i j}\right) \prod_{-j} f\left(x^{i k}, a^{i k}\right)=0$

\footnotetext{
${ }^{10}$ Having assumed that the random factors affecting the quality of each child are i.i.d., a general result in Holmström (1982) allows us to assume that the subsidy optimally accruing to any given agent will depend only on that agent's outcome.

${ }^{11}$ In a sense, therefore, the government acts as an intergenerational intermediary, see Cigno (2005).
} 
where $\lambda$ is the Lagrange-multiplier of the government budget constraint, measuring the marginal social utility of the expected tax revenue, and $\mu^{i j}$ the Lagrange-multiplier of the $i j$ th incentive-compatibility constraint, measuring the marginal social utility of relaxing this constraint. In view of (6), they also tell us that $a^{i j}$ must satisfy ${ }^{12}$

$$
D^{i j}+\lambda E^{i j}+\mu^{i j} F^{i j}=0,
$$

where

$$
D^{i j} \equiv-w^{\prime}\left(a^{i j}\right) U_{2}^{\prime}\left(C_{2}^{i}\right)+\int_{(X)^{n^{i}}} U_{3}\left(C_{3}^{i}\right) f_{a^{i j}}\left(x^{i j}, a^{i j}\right) \prod_{-j} f\left(x^{i k}, a^{i k}\right) \mathbf{d} \mathbf{x}^{i}
$$

is the marginal effect of this variable on $i$ 's expected utility (the marginal private benefit),

$$
E^{i j} \equiv \int_{(X)^{n^{i}}}\left(x^{i j}-y^{i}\right) f_{a^{i j}}\left(x^{i j}, a^{i j}\right) \prod_{-j} f\left(x^{i k}, a^{i k}\right) \mathbf{d} \mathbf{x}^{i} .
$$

its marginal effect on the government budget constraint (the externality), and

$F^{i j} \equiv\left[w^{\prime}\left(a^{i j}\right)\right]^{2} U_{2}^{\prime \prime}\left(C_{2}^{i}\right)-w^{\prime \prime}\left(a^{i j}\right) U_{2}^{\prime}\left(C_{2}^{i}\right)+\int_{(X)^{n^{i}}} U_{3}\left(C_{3}^{i}\right) f_{a^{i j} a^{i j}} \prod_{-j} f\left(x^{i k}, a^{i k}\right) \mathbf{d} \mathbf{x}^{i}$

its marginal effect (negative in second best for $i$ 's second-order condition) on the $i j$ th incentive-compatibility constraint.

\subsubsection{First best}

Suppose, for a moment, that the principal can observe, hence prescribe, $\mathbf{a}^{i}$. As the incentive-compatibility constraints is then slack, $\mu^{i j}$ will be equal to zero, and (9) will reduce to

$$
U_{3}^{\prime}\left(C_{3}^{i}\right)=\lambda
$$

Therefore, the first-best policy equalizes date-3 consumption across agents. In view of (4), it also implies that

$$
y^{i}+\sum_{j=1}^{n^{i}} z\left(x^{i j}\right)=K
$$

\footnotetext{
${ }^{12}$ Strictly speaking, what follows is the first-order condition on $a^{i j}$ only in first best. In second best, this variable is determined by (6), and the equation which follows determines $\mu^{i j}$.
} 
Therefore, the policy gives $i$ full insurance against the risk of a low $\sum_{j=1}^{n^{i}} z\left(x^{i j}\right)$ turnout. ${ }^{13}$ As $U_{3}^{\prime}($.$) is a decreasing function, it then follows$ that the first-best value of $y^{i}$ is decreasing in each element of $\mathbf{x}^{i}$. As $\sum_{j=1}^{n^{i}} z\left(x^{i j}\right)$ is increasing in $n^{i}$, the first-best $y^{i}$ is decreasing also in $n^{i}$. We can then write

$$
y^{i}=y_{F B}\left(\mathbf{x}^{i} ; n^{i}\right),
$$

where $y_{F B}(. ;$.$) is a decreasing function. { }^{14}$

Is there anything we can say about the prescribed $\mathbf{a}^{i}$ ? With $\mu^{i j}$ equal to zero, (10) reduces to

$$
D^{i j}+\lambda E^{i j}=0
$$

As

$\int_{(X)^{n^{i}}} \prod_{j} f\left(x^{i j}, a^{i j}\right) \mathbf{d} \mathbf{x}^{i}=\int_{(X)^{n^{i}-1}} \prod_{-j} f\left(x^{i k}, a^{i k}\right) \mathbf{d} \mathbf{x}^{-i j}=\int_{X} f\left(x^{i j}, a^{i j}\right) d x^{i j}=1$

and

$$
\int_{(X)^{n^{i}}} f_{a^{i j}} \prod_{-j} f\left(x^{i k}, a^{i k}\right) \mathbf{d} \mathbf{x}^{i}=\int_{X} f_{a^{i j}}\left(x^{i j}, a^{i j}\right) d x^{i j}=0,
$$

(14) allows us to re-write (16) as

$$
w^{\prime}\left(a^{i j}\right) U_{2}^{\prime}\left(C_{2}^{i}\right)=U_{3}^{\prime}\left(C_{3}\right) \int_{(X)^{n^{i}}}\left[x^{i j}-y_{F B}^{i}\right] f_{a^{i j}}\left(x^{i j}, a^{i j}\right) \prod_{-j} f\left(x^{i k}, a^{i k}\right) \mathbf{d} \mathbf{x}^{i},
$$

which simplifies to

$$
w^{\prime}\left(a^{i j}\right) U_{2}^{\prime}\left(C_{2}^{i}\right)=U_{3}^{\prime}\left(C_{3}\right) \int_{X}\left[x^{i j}+z\left(x^{i j}\right)\right] f_{a^{i j}}\left(x^{i j}, a^{i j}\right) d x^{i j}
$$

after substituting from (15), because $\sum_{-j} z\left(x^{i k}\right)$ does not depend on $x^{i j}$. This tells us that the marginal private cost of $a^{i j}$ must be equated to the expected marginal social benefit. In the next section, we will find that the first-best value of $U_{2}^{\prime}\left(C_{2}^{i}\right)$ is independent of $n^{i}$. Anticipating that result, and given (14), we then deduce from (17) that the first-best value of $a^{i j}$ does not depend on $n^{i}$. As the agents are differentiated only by the number of children, it then follows that all agents will be required to invest the same amount,

$$
a^{i j}=a_{F B},
$$

in each of their children. The quantity-quality trade-off is gone.

\footnotetext{
${ }^{13}$ Full insurance is a common first-best property. In the standard Principal-Agent problem, however, it arises from the assumption that the principal is less risk-averse than the agents. Here, by contrast, the principal is as risk-averse as the agents, and the property arises from the fact that the principal does not face any risk.

${ }^{14}$ But keep in mind that this function is not differentiable with respect to $n^{i}$, because the number of children can only take values $0,1,2, \ldots$.
} 


\subsubsection{Second best}

Let us now go back to the more realistic assumption that $a^{i j}$ is not observable by the principal. As $i$ has no reason to take into account the effect of $a^{i j}$ on the government budget constraint, we have a moral hazard problem. The incentive-compatibility constraints (6) will then be tight, and $\mu^{i j}$ will be positive for every $i j$. Re-writing (9) as

$$
\frac{\lambda}{U_{3}^{\prime}\left(C_{3}^{i}\right)}=1+\sum_{j=1}^{n^{i}} \mu^{i j} \frac{f_{a^{i j}}\left(x^{i j}, a^{i j}\right)}{f\left(x^{i j}, a^{i j}\right)},
$$

we can see that the second-best $y^{i}$ depends on $\mathbf{x}^{i}$. Recalling that, at this date, the agents are differentiated by number of children, the date- 3 subsidy schedule will be parameterized by $n^{i}$,

$$
y^{i}=y_{S B}\left(\mathbf{x}^{i} ; n^{i}\right) .
$$

As $U_{3}^{\prime}($.$) is a decreasing function, and recalling that \frac{f_{a^{i j}}\left(x^{i j}, a^{i j}\right)}{f\left(x^{i j}, a^{i j}\right)}$ is increasing in $x^{i j}$, the second-best value of $C_{3}^{i}$ is clearly increasing in $\mathbf{x}^{i}$. What does this imply about $y_{S B}\left(., n^{j}\right)$ ? Recall that $C_{3}^{i}$ increases with $y^{i}+\sum_{j=1}^{n^{i}} z\left(x^{i j}\right)$. Recall also that, in first best, $y^{i}$ is decreasing in $\mathbf{x}^{i}$ for insurance reasons. In second best, however, the policy must give $i$ the incentive to invest more in each child. For that purpose, $y^{i}$ should then be increasing in $\mathbf{x}^{i}$. The tension between incentive and insurance considerations makes the second-best effect of $x^{i j}$ on $y_{S B}^{i}$ ambiguous. Since $z^{\prime}$ (.) is positive and decreasing, insurance is likely to be the predominant consideration at low realizations of $x^{i j}$, but the incentive consideration is likely to be paramount at high ones. Therefore, the graph of the second-best relationship between $y^{i}$ and $x^{i j}$ is likely to be U-shaped.

Given $y_{S B}\left(. ; n^{i}\right)$, agent $i$ will invest the same amount in each of its $n^{i}$ children,

$$
a^{i j}=a_{S B}^{i}
$$

We cannot sign the effect of $n^{i}$ on $a_{S B}^{i}$. An increase in $n^{i}$ will in fact reduce the marginal opportunity-cost of $a_{S B}^{i}, w^{\prime}\left(a_{S B}^{i}\right) U_{2}^{\prime}\left(C_{2}^{i}\right)$. Depending on all the parameters of the model, however, it may raise or lower the marginal incentive-cost. If the latter rose sufficiently fast, the secondbest policy would not get rid of the quantity-quality trade-off.

\section{Date-1 decisions}

Having seen how the principal, and agent $i$, will behave a date 2 conditional on $n^{i}$, we can predict how they will make their choices at date 1 . 
The number of children born to $i$ at date $2, n^{i}$, depends on an action undertaken by $i$ at date $1, b^{i}$, and on a random variable, $\zeta^{i}$. As we did with regard to $x^{i j}$, we shall treat $n^{i}$ itself as a random variable, and assume that the probability of this variable is identically and independently distributed across agents. In recognition of the fact that $n^{i}$ can only take values $0,1,2, \ldots$, we write its density in the discrete form $p\left(n^{i}, b^{i}\right)$. Having interpreted $b^{i}$ as reproductive activity, the cumulative distribution of $n^{i}$ associated with a higher $b^{i}$ will first-order stochastically dominate the one associated with a lower $b^{i}$. As we did with reference to $f\left(x^{i j}, a^{i j}\right)$, we assume that $p\left(n^{i}, b^{i}\right)$ satisfies the standard MLR (meaning, in the present context, that $\frac{p_{b^{i}}\left(n^{i}, b^{i}\right)}{p\left(n^{i}, b^{i}\right)}$ is increasing in $\left.b^{i}\right)$ and CDF conditions. Among other things, these assumptions ensure that $i$ 's expected date-1 utility is concave in $b^{i}$. We further assume that reproductive activity in itself bears no cost.

\subsection{Agents}

At date 1 , agent $i$ chooses $b^{i}$ to maximize.

$$
W_{1}^{i}=U_{1}\left(C_{1}^{i}\right)+\sum_{n^{i}} p\left(n^{i}, b^{i}\right)\left[U_{2}\left(C_{2}\left(n^{i}\right)\right)+U_{3}\left(C_{3}\left(n^{i}\right)\right)\right]
$$

where $C_{t}\left(n^{i}\right)$ denotes the value of $C_{t}^{i}$ maximized with respect to $\mathbf{a}^{i}$, for any given $n^{i}$. In other words, couples choose their level of reproductive activity at date 1 knowing that, at date 2, they will optimally choose how much to invest in any children who might be born as a result.

The first-order condition for the maximization of (20),

$$
\sum_{n^{i}} p_{b^{i}}\left(n^{i}, b^{i}\right)\left[U_{2}\left(C_{2}\left(n^{i}\right)\right)+U_{3}\left(C_{3}\left(n^{i}\right)\right)\right]=0,
$$

tells us that $i$ will raise $b^{i}$ to the point where the expected private marginal benefit equals the current marginal cost. The latter is zero for the assumption that reproductive activity costs nothing. The cost will come at date 2 , if any children are actually born. The expected value of this cost is reflected in $C_{2}$ (.).

\subsection{Principal}

As $N$ is large, and having assumed that $n^{1}, \ldots, n^{N^{i}}$ are i.i.d., the government does not face uncertainty with regard to either the aggregate value of the subsidies it will have to pay at date $2, \sum_{i=1}^{N} \sum_{n^{i}} p\left(n^{i}, b^{i}\right) s^{i}$, or the net aggregate tax revenue it will receive at date $3, \sum_{i=1}^{N} \sum_{n^{i}} p\left(n^{i}, b^{i}\right) \int_{(X)^{n^{i}}} \sum_{j=1}^{n^{i}}\left(x^{i j}-y^{i}\right) \prod_{j} f\left(x^{i j}, a^{i}\right.$ 
The principal will then choose $n^{i}, i=1,2, \ldots, N$, and an $s^{i}$ for each possible realization of $n^{i}$, so as to maximize

$$
W_{1}=\sum_{i=1}^{N}\left\{U_{1}\left(C_{1}^{i}\right)+\sum_{n^{i}} p\left(n^{i}, b^{i}\right)\left[U_{2}\left(C_{2}\left(n^{i}\right)\right)+U_{3}\left(C_{3}\left(n^{i}\right)\right)\right]\right\},
$$

subject to

$$
\sum_{i=1}^{N} \sum_{n^{i}} p\left(n^{i}, b^{i}\right) s^{i} \leq \sum_{i=1}^{N} \sum_{n^{i}} p\left(n^{i}, b^{i}\right) \int_{(X)^{n^{i}}} \sum_{j=1}^{n^{i}}\left(x^{i j}-y^{i}\right) \prod_{j} f\left(x^{i j}, a^{i j}\right) \mathbf{d} \mathbf{x}^{i},
$$

and to the incentive-compatibility constraints (21). This problem differs from the one solved at date 2 in that $n^{i}$ is still a random variable, and $s($.$) is yet to be determined. As at date 2$, however, there is no need for participation constraints, because the income tax is given, and no agent will turn down the offer of a subsidy.

The first-order condition on the principal's choice of $s^{i}$ is

$$
p\left(n^{i}, b^{i}\right)\left[U_{2}^{\prime}\left(C_{2}^{i}\left(n^{i}\right)\right)-v\right]+\gamma^{i} U_{2}^{\prime}\left(C_{2}^{i}\left(n^{i}\right)\right) p_{b^{i}}=0,
$$

where $\gamma^{i}$ is the Lagrange-multiplier of the incentive-compatibility constraint (21), and $v$ the Lagrange-multiplier of the government's date-1 budget constraint (23). As all the agents are now alike,

$$
\gamma^{i}=\gamma
$$

We can then re-write (24) as

$$
\frac{v}{U_{2}^{\prime}\left(C_{2}^{i}\right)}=1+\gamma \frac{p_{b}\left(n^{i}, b^{i}\right)}{p\left(n^{i}, b^{i}\right)} .
$$

If $b^{i}$ were observable, the incentive-compatibility constraint (21) would not be binding, and the solution would then give us the first-best policy. As $\gamma$ would then be zero, (25) would reduce to

$$
U_{2}^{\prime}\left(C_{2}(n)\right)=v
$$

Therefore, the first-best policy equalizes date- 2 consumption across agents and states of nature. In view of (3), and given that $U_{2}^{\prime}($.$) is decreasing,$ and $c($.$) increasing, if s^{i}$ were non-increasing in $n^{i}, C_{2}^{i}$ would be decreasing in $n^{i}$. Therefore, in first best,

$$
s^{i}=s_{F B}\left(n^{i}\right),
$$


where $s_{F B}($.$) is an increasing function. .^{15}$

Since reproductive behaviour is not observable, however, and given that $i$ has no reason to take into account the effect of $b^{i}$ on the principal's budget constraint, there is another a moral hazard problem. The incentive-compatibility constraint (23) will then be binding, and the principal's optimization will yield a second-best policy. Having assumed

that $\frac{p_{b}\left(n^{i}, b^{i}\right)}{p\left(n^{i}, b^{i}\right)}$ is increasing in $n^{i}$, the second-best value of the date-2 subsidy is

$$
s^{i}=s_{S B}\left(n^{i}\right),
$$

where $s_{S B}($.$) is an increasing function like s_{F B}($.$) . In first best, however,$ the only reason for promising higher subsidies to the agents will have more children is to compensate them for the additional cost they have to bear at date 2 . In second best, by contrast, there is also an incentive reason. Therefore, an extra birth will raise the date- 2 subsidy more in second than in first best.

\section{Discussion}

We have examined a situation where the quantity (number) of children born to a couple, and the qualities (lifetime earning and thus, for any given income-tax schedule, tax-paying capacities) of these children, are random variables with known density conditional on actions undertaken by the couple. The action which conditions the probability distribution of the quantity of children is interpreted as reproductive activity, the one which conditions the probability distribution of a child's quality as educational investment in the broadest sense (money and attention spent on the child). A couple, therefore, can effectively choose the probability distribution of the quantity of children by choosing its level of reproductive activity, and the probability distribution of a child's quality by choosing how much to invest in the child. The realized quantity and qualities of each couple's children are observable by everyone concerned, but the couple's level of reproductive activity, and the amounts it invested in these children are private information. Couples derive either direct or indirect utility from their children's quality. The government derives utility from that of each couple.

We have identified two justifications for government intervention. The first one arises from the fact that a couple's behaviour has an effect on the government's future tax revenue, but the couple has no reason to take this effect into account in choosing how to behave. Having assumed that this behaviour is not observable by the government, there is then a moral hazard problem. The second justification follows from the

\footnotetext{
${ }^{15}$ As the number of children is a discrete variable, this function is not differentiable.
} 
assumption that quantity and quality are identically and independently distributed. While couple face risks in respect of both these variables, therefore, the government does not face any risk with regard to its future tax revenue. Partly as a consequence of this asymmetry, we have assumed that the former are not allowed to borrow against their children's expected earnings, while the latter is free to borrow against its future tax revenue. In addition to a general income tax, assumed given, the optimal policy uses two subsidies, one payable when the quantity of children is known, the other when their qualities of these children are revealed. Quality may vary across children even if they received the same treatment from their parents, because each is the result of an independent draw. The subsidy payable when the children are born may be interpreted as a family allowance. The one payable when the children's qualities are revealed lends itself to two possible interpretations. As a person's earning capacity can be reliably assessed only when this person is in middle life, and his or her parents on the point of retirement, it seems natural to interpret this second subsidy as a pension entitlement. ${ }^{16}$ Alternatively, and to the extent that scholastic performance is a predictor of a student's future earning capacity, the subsidy can be interpreted as the sum of the scholarships payable to a couple's school-age children, ${ }^{17}$ Each of these scholarships will depend not only on the child's own scholastic performance, but also on the performance of each of the child's siblings.

The policy optimization has a Principal-Agent format, with the government in the role of principal, and couples in that of agents. In first best, private behaviour is observable. The government can then order each couple to undertake the first-best level of reproductive activity, which turns out to be the same for all couples, and to invest the firstbest quantity of money and own time, the same for all children and all couples, in each child who happens to be born. The first-best subsidy payable as soon as the children are born is increasing in the quantity of children. The one payable when the qualities of these children become known is decreasing in these qualities. This policy redistributes in favour of couples with more children, and with less able children, and provides all couples with full insurance. In second best, private behaviour is not observable. As the government can neither tell couples what to do in

\footnotetext{
${ }^{16}$ For a pension reform proposal based on the principle that a working-age person should have an incentive to produce future contributive capacity, see Cigno (2009).

${ }^{17}$ Interpreting it a sum of university scholarships is less appropriate, because parents do not have the same degree of control over their university-age children as over their school-age ones. For an analysis of university scholarships, see Cigno and Luporini (2009).
} 
the bedroom, nor order parents to invest in any child at any specified level, it must then give them the incentive to do so. The second-best subsidy payable when the children are born is still increasing in the number of children, but rises faster than in first best because incentive and redistribution considerations pull in the same direction. By contrast, the subsidy payable when the qualities of these children are revealed is the result of a compromise between insurance or redistributive considerations on the one hand, and incentive considerations on the other. This subsidy is then likely to be decreasing in the quality of each of the couple's children at low realizations of this variable, increasing at high ones.

How does the second-best policy applicable to the case examined here differ from the one applicable in the one where a couple can deterministically choose how many children to have? The latter is examined in Cigno, Luporini and Pettini (2003). There, a couple can be ordered to (threatened with a severe penalty if it does not) procure the second-best number of children. As there is then no need for the government to offer couples costly fertility incentives as in the present case, the policy uses only one instrument, a child-specific subsidy dependent on the child's own quality. ${ }^{18}$

\section{References}

Balestrino, A., A. Cigno and A. Pettini (2002), Endogenous Fertility and the Design of Family Taxation, International Tax and Public Finance 9, $175-193$

Cigno, A. (1986), Fertility and the Tax-benefit System: A Reconsideration of the Theory of Family Taxation, Economic Journal 96, 10351051

(1993), Intergenerational Transfers Without Altruism: Family, Market and State, European Journal of Political Economy 9, 505-518 (2005), The Political Economy of Intergenerational Cooperation, in S. Kolm and J. Mercier-Ythier (eds.), Handbook of Giving, Reciprocity and Altruism (Handbooks in Economics Series edited by K. J. Arrow and M. D. Intriligator), Amsterdam: North-Holland

- (2009), How to Avoid a Pension Crisis. A Question of Intelligent Mechanism Design, CESifo Economic Studies, forth. and A. Luporini (2009), Scholarships or Student Loans? Subsidizing Higher Education in the Presence of Moral Hazard, Journal of Public Economic Theory 11, 55-87

\footnotetext{
${ }^{18}$ The subsidy depends only on the child's own quality because, in the article, it is assumed that all the children who receive the same treatment will perform the same.
} 
, A. Luporini, and A. Pettini (2003), Transfers to Families with Children as a Principal-Agent Problem, Journal of Public Economics $87,1165-1177$

(2004), Hidden Information Problems in the Design of Family Allowances, Journal of Population Economics 17, 645-655

Cremer, H., A. Dellis and P. Pestieau (2003), Family Size and Optimal Income Taxation, Journal of Population Economics 16, 37-54

Eckstein, Z. and K. I. Wolpin (1985), Endogenous Fertility and Optimum Population Size, Journal of Public Economics 27, 93-106

Granovetter, M. (1995), Getting a Job: A Study of Contacts and Careers, 2nd Edition, Chicago, University of Chicago Press

Grossman, S. and O. Hart (1983), An Analysis of the Principal-Agent Problem, Econometrica, 51, 7-45

Holmström, B. (1979), Moral Hazard and Observability, Bell Journal of Economics 10, 74-91

nomics $13,324-340$

Luporini, A, (2006), Relative Performance Evaluation in a MultiPlant Firm, Economic Theory, 28, 235-243

Michel, Ph. and P. Pestieau (1993), Population Growth and Optimality. When Does Serendipity Hold?, Journal of Population Economics 6, 353-362

Mirrlees, J. A. (1974), Notes on Welfare Economics, Information and Uncertainty, in M. S. Balch, D. L. McFadden and S. Y. Wu (eds.) Essays on Economic Behavior and Uncertainty, Amsterdam: North-Holland

Peters, W. (1995), Public Pensions, Family Allowances and Endogenous Demographic Change, Journal of Population Economics 8, 161-183

Razin, A. and E. Sadka (1995), Population Economics, Cambridge Mass.: MIT Press

Rogerson, W. (1985), The First-Order Approach to Principal-Agent Problems, Econometrica, 53, 69-76.

Sinn, H.-W. (2004), The Pay-As-You-Go Pension System as Fertility Insurance and Enforcement Device, Journal of Public Economics 88, $1335-1357$ 